
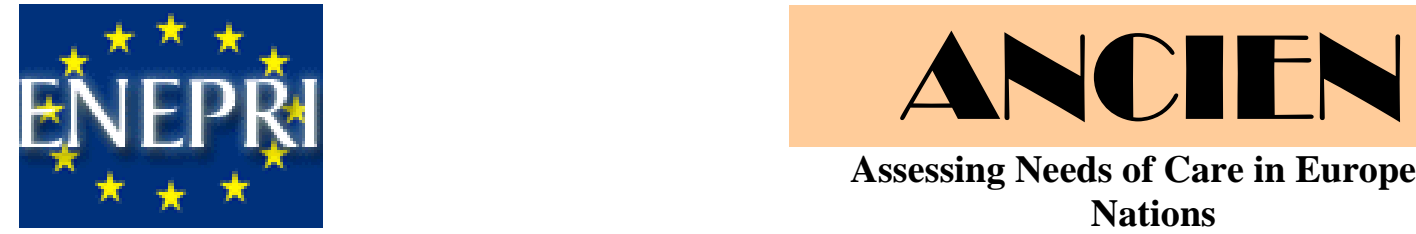

Assessing Needs of Care in European

European Network of Economic Nations

Policy Research Institutes

\title{
DeMographic EPIDEMiologic Projections OF LONG-TERM CARE NEEDS IN SELECTED EUROPEAN COUNTRIES \\ GERMANY, SPAIN, THE NETHERLANDS AND POLAND
}

\author{
LUC BONNEUX, NICOLE VAN DER GAAG, \\ GOVERT BIJWAARD, ESTHER MOT AND PETER WILlEMÉ
}

\author{
ENEPRI POLICY BRIEF No. 8
}

FEBRUARY 2012
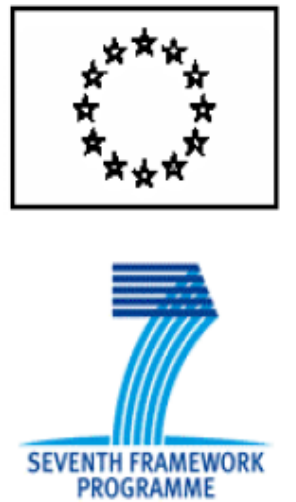

ANCIEN website (http://www.ancien-longtermcare.eu/

(C) Copyright 2012 Luc Bonneux, Nicole Van der Gaag, Govert Bijwaard, Esther Mot and Peter Willemé

ENEPRI Policy Briefs extract the policy implications of research carried out by member institutes of the European Network of Economic Policy Research Institutes. Initiated by CEPS in 1999, ENEPRI conducts research on welfare and employment issues with the aim of diffusing research, coordinating research plans and increasing the awareness of the European dimension in national problems (see www.enepri.org). The research presented in this Policy Brief was conducted under the ANCIEN project (Assessing Needs of Care in European Nations), which focuses on the future of longterm care for the elderly in Europe. Funding for the project is received from the European Commission under the $7^{\text {th }}$ Framework Programme (FP7 Health-2007-3.2.2, Grant no. 223483). See the back page for more information “About ANCIEN”. The results and conclusions of this paper are those of the authors and are not attributable to Eurostat, the European Commission or any of the national authorities whose data have been used. The views expressed are attributable only to the authors in a personal capacity and not to any institution with which they are associated.

Available for free downloading from the CEPS website (www.ceps.eu) and 


\title{
Demographic EPIDEMiologic Projections OF LONG-TERM CARE NEEDS IN SELECTED EUROPEAN COUNTRIES Germany, SPAin, THE NeTHERLANDS AND Poland
}

\author{
LuC BONNEUX, NICOLE VAN DER GAAG, GOVERT BIJWAARD,
} Esther Mot AND Peter WillemÉ ${ }^{*}$

\author{
ENEPRI POLICY BRIEF No. 8/FEBRUARY 2012
}

\begin{abstract}
Summary
The objectives of Work Package (WP) 2 of the EU FP7 project ANCIEN are to assess the actual and future numbers of elderly care-dependent persons in selected countries. Such projections are needed to support planning to meet future needs for long-term care (LTC) across the EU. We have selected four countries for projections of LTC needs: Spain, Poland, Germany and the Netherlands. These countries are representative of European epidemiology and of different systems for the provision of long-term care.

We have used the mortality forecasts of the EUROPOP 2008 scenarios as a basis for projections of the number of disabled elderly persons, according to several assumptions about how disability and mortality are related. We have added scenarios on the effects of smoking and obesity (BMI). Data have also been derived from Eurostat (forecasts of mortality and populations), ANCIEN WP 1 (the elderly living in institutions), the SHARE project (the elderly living in the community) and the Rotterdam Study (on ageing).

The main determinant of the future numbers of the disabled elderly has turned out to be the demographic ageing of the large baby boom cohorts. This is projected to cause increases of $44 \%$ (Germany), 65\% (Spain), 82\% (the Netherlands) and 57\% (Poland). The impact of life extension depends on the correlation of disability in old age and mortality, and is moderate under reasonably conservative assumptions (with rises of $11 \%$ for Germany, $7 \%$ for Spain, $9 \%$ for the Netherlands and $22 \%$ for Poland). For Poland, convergence with Germany on the onset of disability in terms of timing would limit this increase. Obesity and (quitting) smoking have little effect - increasing levels of disability by around 2 percentage points per absolute increase in the prevalence of obesity of $5 \%$, while quitting smoking has even less effect.
\end{abstract}

We conclude that the future numbers of long-term care recipients can be robustly predicted and will be mainly determined by demographic ageing.

\footnotetext{
* Luc Bonneux, Nicole Van der Gaag and Govert Bijwaard are Senior Researchers at the Netherlands Interdisciplinary Demographic Institute (NIDI), The Hague. Esther Mot is a Researcher at CPB Netherlands Bureau for Economic Policy Analysis, The Hague and Peter Willemé is Health Economist at the Federal Planning Bureau (FPB), Brussels. Peter Willemé and Esther Mot are Scientific Coordinators of the ANCIEN project. Comments or questions can be addressed to Nicole Van der Gaag (gaag@nidi.nl).

The authors wish to gratefully acknowledge the positive comments and support of the other members of the ANCIEN project (http://www.ancien-longtermcare.eu/). Joop de Beer, Senior Researcher and Head of Population Dynamics Department at NIDI, initially gave advice on how to set up the more simplified forecasting models, usable in conditions of scarce data.
} 
What is known:

- The large post-War baby boom cohorts start to turn 65 in 2011, bringing large increases in the shares of the population aged 65 and older in Europe.

- These cohorts will live to older ages with apparently higher risks of age-related disability.

- Changes in smoking and obesity may increase the prevalence of disability further.

What this project has added:

- Evidence shows that life extension is correlated with life extension free of (severe) disability; this will limit the increase in the prevalence of disability in populations living to older ages.

- Lower smoking rates increase survivorship, but have only a small effect on the prevalence of disability.

- A higher prevalence of obesity increases the prevalence of disability attributable to obesity, but this increase is relatively limited compared with the demographic growth in the numbers of the elderly.

Relevance for European policies on long-term care:

- The prevalence of the (severely) disabled elderly can be robustly estimated, and it largely depends on the demography of the population aged 65 and older.

- For a better understanding of the European epidemiology of (severe) disability, more data on the incidence, prevalence and recovery at older ages are urgently needed.

\section{Introduction: Defining and forecasting long-term care needs}

The large post-War baby boom began in 1946 and its cohorts reached the retirement age of 65 starting in 2011. A ‘baby crash' (a sharp decline in fertility) followed the baby boom. This imbalance between the large baby boom generations and the small baby crash generations born after the 1970s determines future population ageing: large numbers of elderly persons aged 65+ followed by few adults. Policy questions related to the provision of health and long-term care services in an ageing population need reliable forecasts of the numbers of disabled elderly persons. In this Policy Brief, we use demographic models to project the future need for long-term care in four countries of the EU: Germany (DE), Spain (ES), the Netherlands (NL) and Poland (PL), based on the EUROPOP 2008 mortality forecasts (Giannakouris, 2010). The methods developed are generic and easily applicable to all countries that can produce mortality data and prevalence data on limitations in activities of daily living (ADLs) and selected risk factors.

Disability and morbidity are descriptions of health states with many dimensions. We are most interested in severe disability, leading to a loss of independence and the need for help in self care (Katz et al., 1963). This is operationalised as having at least one limitation in basic activities of daily living (subsequently referred to as an ADL disability), defined as self-reported difficulty with any of the following actions: a) bathing, b) dressing, c) eating, d) indoor transfers and e) toileting and continence.

The prevalence of disability is determined by incidence and survival in that state. To assess dynamic changes in populations, we need information on dynamic change - how people flow into disability and out of life (Barendregt, Bonneux and Van der Maas, 1994). Projections of disability are based on the future numbers of persons entering old age (demographic change), the length of time they will live as elderly individuals (mortality and life expectancy), the probability that they will become disabled and the length of time they will survive being disabled (epidemiology of disability).

We seek answers to three questions. First, what will be the consequences of the demographic increase of elderly cohorts? Second, what will be the consequences of the life extension of these cohorts (sometimes called 'double ageing')? And third, what will be the consequences of a changing 
epidemiology with the known effects on disability of smoking and obesity (Reuser, Bonneux and Willekens, 2009)?

The EUROPOP 2008 forecasts are the basis of our demographic and mortality forecasts. The first question is answered by baseline demographic projections assuming constant mortality and incidence after age 55, projecting the forecasted increase of populations reaching age 55 in the period 2008-60. Information on the numbers of the disabled elderly currently living in the community is taken from the large European study, SHARE (the Survey of Health, Ageing and Retirement in Europe), ${ }^{1}$ complemented with estimates of the numbers of the elderly living in institutions, derived from WP 1 of the ANCIEN project.

The second question is answered by the forecasted mortality at age 65 and older, and by the relation between disability and mortality. This relation is determined by ageing: age since birth as a proxy of wear and tear (or chronology, 'Chron' in our scenarios) and age before death as a proxy of biological age, characterising the resilience of the organism against the ageing process ('Biol', from biology in our scenarios). The effect of increasing life expectancy is assessed by three scenarios studying different morbidity scenarios. A chronological scenario (Chron) assumes increasing life expectancy but a constant incidence of age-specific disability. This is an "expansion of morbidity scenario", predicting longer life by increased survival of the diseased (Manton, 1982; Olshansky et al., 1991). The biological scenario (Biol) assumes equal trends in mortality and disability (Cai and Lubitz, 2007; Christensen et al., 2009; Manton, 1982; Mitnitski et al., 2002; Payne et al., 2007). A similar but more conservative scenario assumes that the incidence of disability is delayed similar to mortality ('Delay'). The former socialist countries of Europe, here exemplified by Poland, are lagging behind in life expectancy. The EUROPOP scenarios (and most scholars) assume that these countries will catch up: mortality scenarios assume convergence. Therefore, we have also added a scenario of future convergence in terms of disability in Poland ('Convergence').

The third question is answered by epidemiologic scenarios. We modelled the effects of lifestyles (smoking and obesity) as categorical variables. Gender- and age-specific mortality by disability were identified by using data from the Rotterdam Study Project (Hofman et al., 2009) and the prevalence conditional on risk factors was defined by the SHARE study.

\section{Evidence and analysis}

In Germany, life expectancy for women at age 65 was 20.1 years and for men it was 16.8 years in 2008. This life expectancy is split into two parts: disabled and not disabled. German men were expected to live 3.3 years with an ADL disability and German women 4.8 years (reflecting the higher prevalence of disability among women). Women experience disability more often than men; also, the prevalence of disability is very low among Dutch men and a bit higher among Spanish women. Poland is characterised by a high mortality rate, particularly among men, and a high prevalence of disability. Such a rapid age-related decline in physical function has also been documented in Russia (Bobak et al., 2004).

The EUROPOP 2008 scenario assumes that in 2040, more than three years of life expectancy are added by lowered mortality (somewhat more than a year per decade). In a biological scenario, the increase in the duration of disability would be close to nil (data not shown): this scenario assumes that late-age disability is timed by the date of death, not by the date of birth, so life extension postpones both death and disability and solely adds healthy years. In a chronological scenario, half of the gained life expectancy is spent in disability (data not shown). This reflects the high prevalence of disability at older ages, but assumes that disability at old age and mortality are independent processes. In the less extreme Delay scenario (shown in Table 1), the increase in the duration of disability is more moderate. The scenario of Poland's convergence with Germany on disability incidence shows that even a strong assumption of convergence (with an equal disability incidence in 2040) will still have a limited effect on disability prevalence (not shown): reducing flows (incidence) has a slow effect on the remaining shares (prevalence).

\footnotetext{
${ }^{1}$ See the SHARE website at http://www.share-project.org/.
} 
Table 1. Life expectancies at age 65, by period (2008 and 2040), gender and disability status

\begin{tabular}{|c|c|c|c|c|c|c|}
\hline & \multicolumn{2}{|l|}{$\mathbf{F}$} & \multicolumn{3}{|c|}{$\mathbf{M}$} & \multirow[b]{2}{*}{$\mathbf{D e}_{65}$} \\
\hline & $\mathbf{e}_{65}$ & $\mathbf{n D e}_{65}$ & $\mathbf{D e}_{65}$ & $\mathbf{e}_{65}$ & $\mathbf{n D e}_{65}$ & \\
\hline \multicolumn{7}{|l|}{ Germany } \\
\hline 2008 & 20.10 & 15.35 & 4.75 & 16.87 & 13.56 & 3.32 \\
\hline 2040 Delay & 23.34 & 17.78 & 5.56 & 20.37 & 16.25 & 4.12 \\
\hline \multicolumn{7}{|l|}{ Spain } \\
\hline 2008 & 20.96 & 14.87 & 6.09 & 17.14 & 13.79 & 3.35 \\
\hline 2040 Delay & 23.89 & 17.02 & 6.87 & 20.48 & 16.37 & 4.11 \\
\hline \multicolumn{7}{|c|}{ The Netherlands } \\
\hline 2008 & 19.94 & 15.64 & 4.30 & 16.59 & 14.39 & 2.20 \\
\hline 2040 Delay & 23.25 & 18.26 & 4.99 & 19.99 & 17.26 & 2.73 \\
\hline \multicolumn{7}{|l|}{ Poland } \\
\hline 2008 & 18.56 & 10.85 & 7.71 & 14.50 & 9.91 & 4.59 \\
\hline 2040 Delay & 22.37 & 12.89 & 9.48 & 18.77 & 12.45 & 6.31 \\
\hline Convergence & 22.62 & 14.47 & 8.14 & 19.05 & 13.44 & 5.61 \\
\hline
\end{tabular}

Notes: $\mathrm{F}$ is female, $\mathrm{M}$ is male, $\mathrm{e}_{65}$ is life expectancy, $\mathrm{nDe}_{65}$ is life expectancy free of disability and $\mathrm{De}_{65}$ is life expectancy with disability, all at age 65. For scenarios, see text.

To the individual life expectancies of Table 1, we have added the population effects of demography, in order to show the developments in the number of the disabled elderly (Figure 1).

Figure 1. Change in basic ADLs among the disabled elderly in 2040 compared with 2008

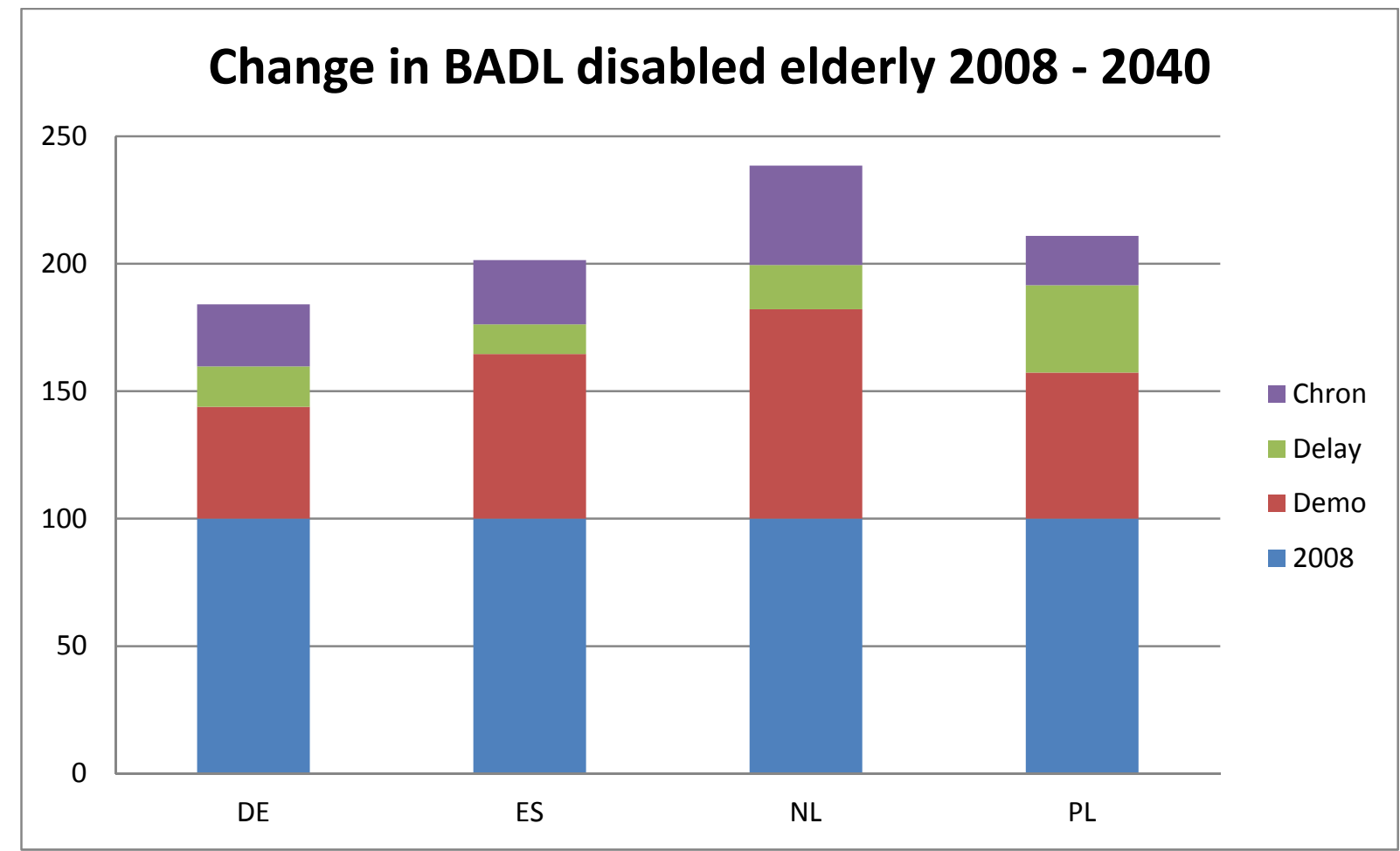

Notes: 'Demo' is the expected change assuming constant mortality and incidence. Life extension adds the numbers of the intermediate 'Delay' scenario. 'Chron' adds the numbers if the incidence of disability remained constant. 
If incidence and mortality remain constant, all increases will be caused by demographic increases alone. In Germany, the increase in the elderly caused by the baby boom will be low (+44\%), while it will be high in the Netherlands (+82\%) and intermediate in Poland and Spain (respectively $+57 \%$ and $+65 \%$ ). A constant disability incidence (or prevalence) but lowered mortality rate would be a 'worst case disability scenario' (Chron). In most countries, the prevalence of disability would double. In the Netherlands, the number of the disabled elderly would even increase by an additional $140 \%$. The somewhat more optimistic Delay scenario shows the effect of a modest decline in the disability incidence. In Germany, the Netherlands and Spain, the increase in disability by life extension combined with a delay in the onset of disability would be between 7 and $11 \%$, caused by ageing. In Poland, this figure would be $22 \%$, a consequence of the high prevalence of disability and more pronounced increases in life expectancy. If mortality converges, however, it is not reasonable to assume no convergence of disability. Convergence with Germany would limit the effects of life extension on disability by 5 percentage points, mostly as a consequence of a historically high prevalence of disability. But it would never fall under a demographic scenario.

Table 2 shows the consequences of differences in the risk factors of obesity and smoking for the cohorts in the German life table. Relative mortality weights for obesity and smoking are based on the studies of Walter et al. (2009) and Majer et al. (2011b). With risk factor-specific prevalence of disability, we are able to calculate the risk factor-specific incidence of disability (van der Gaag et al., 2012). For reasons of brevity, only Germany is shown.

Table 2. Healthy life expectancies at age 65 by risk factor status in 2008

\begin{tabular}{lrrrrrr}
\hline $\mathbf{2 0 0 8}$ & \multicolumn{2}{c}{ Women } & \multicolumn{3}{c}{ Men } \\
& $\mathbf{e}_{65}$ & $\mathbf{n D ~ e}_{65}$ & $\mathbf{D ~ e}_{65}$ & $\mathbf{e}_{65}$ & $\mathbf{n D ~ e}_{65}$ & $\mathbf{D ~ e}_{65}$ \\
\hline Germany & & & & & & \\
EUROPOP & 20.07 & - & - & 16.82 & - & - \\
ANCIEN & 20.10 & 15.35 & 4.75 & 16.87 & 13.56 & 3.32 \\
nS & 20.33 & 15.49 & 4.84 & 17.33 & 13.87 & 3.46 \\
S & 16.47 & 13.13 & 3.34 & 13.66 & 11.49 & 2.16 \\
nO & 20.22 & 15.88 & 4.34 & 16.92 & 13.59 & 3.33 \\
O & 19.73 & 13.39 & 6.33 & 16.56 & 13.09 & 3.47 \\
\hline
\end{tabular}

Notes: $\mathbf{e}_{65}$ is life expectancy, $\mathrm{nD} \mathbf{e}_{\mathbf{6 5}}$ is life expectancy free of disability and $\mathrm{D} \mathbf{e}_{\mathbf{6 5}}$ is life expectancy with disability. NS and NO and are non-smokers and non-obese persons, respectively, while S is smokers and $\mathrm{O}$ is obese persons. All data are in years.

Smoking decreases the duration of disability by a high mortality rate (Barendregt, Bonneux and van der Maas, 1997; Al Mamun et al., 2004; Reuser, Bonneux and Willekens, 2009). Obesity increases the risks of disability, particularly among women. ${ }^{2}$ Smokers' life expectancy is nearly 4 years shorter. The lives of obese individuals are not much shorter, but those of obese women are nearly 2.5 years shorter in which they are free of disability, and two years longer with a disability. The scenarios assume that future mortality and incidence are risk factor-dependent, but that the changes over time in mortality and incidence are risk factor-independent (the forecasted changes, in \% per year, are equal among the obese and non-obese).

Figure 2 shows the consequences of different obesity scenarios. The 'Lean' scenario assumes that the prevalence of obesity will halve (and reach the levels of the 1960s again). The 'Fat' scenario assumes that the prevalence of obesity will double (and reach the levels of the US). These scenarios are extreme, as we assume the change to have occurred in 2008.

\footnotetext{
${ }^{2}$ See Al Snih et al. (2007), Alley and Chang (2007), Peeters et al. (2004), Reuser, Bonneux and Willekens (2009), Sturm, Ringel and Andreyeva (2004), Walter et al. (2009) and Majer et al. (2011b).
} 
Figure 2. Change in ADLs among the disabled elderly in 2040 compared with 2008, obesity scenarios

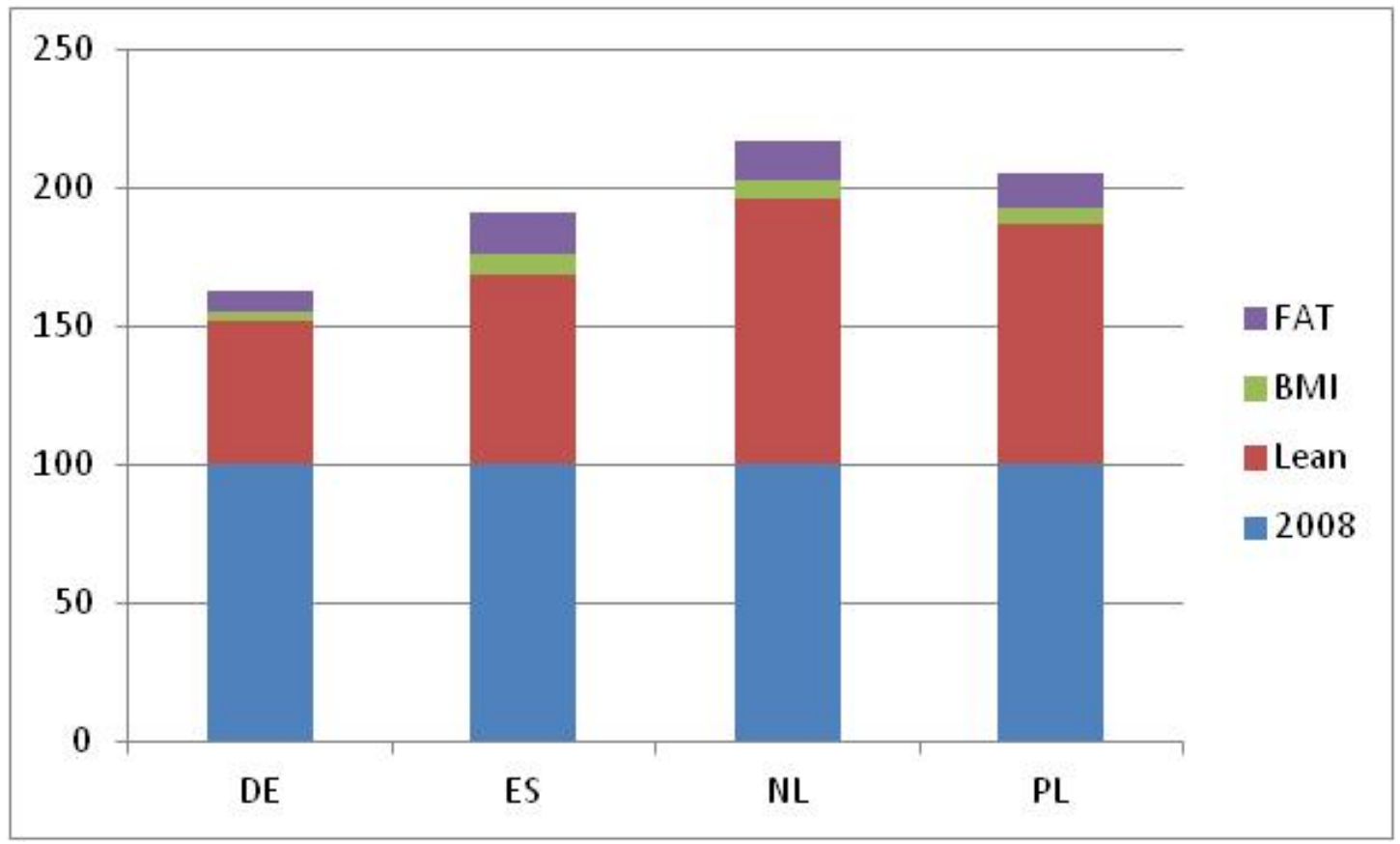

Notes: The obesity scenarios show the consequences of the Delay scenario adjusted for heterogeneity in BMI. In 'Lean', the prevalence of obesity in the future cohorts halves. 'BMI' adds the numbers of disabled persons when the prevalence of obesity remains constant at the values of 2008. In 'Fat' the prevalence of obesity doubles.

But even these extreme scenarios, with large consequences for the individual life course, have a rather limited impact on the prevalence of disability. Every individual born before 1975 will contribute to the prevalence of disability among those aged 65+ in 2040, while only the obese fraction in that population can contribute to the excess prevalence of disability, caused by obesity.

Smoking trends are implicitly taken into account by the EUROPOP 2008 forecast methodology. These have been a major cause of the mortality decline among men in European democracies since the 1970s, but not among European women, born before the Second World War: by societal consensus, these generations of girls were not allowed to smoke. This changed after the War. The female baby boom generation took up smoking in large(r) numbers, and will pay the price with increased mortality. In general, this means that the future decline of female mortality is overestimated by the EUROPOP mortality scenario, while the future decline of male mortality is underestimated.

As shown in Figure 3, 'Smok' adds the numbers of disabled persons when the prevalence of smoking remains constant at the values of the young cohorts in 2008. This ignores the successful quitting of future diseased smokers: due to a (very) high mortality rate among disabled smokers who do not quit, ignoring this possibility would lower disability. 'Trend' is a realistic scenario assuming a slowly declining prevalence (2\% per year) and successful quitting at a rate of $2 \%$ per year. 'Quit' is an accelerated quitting scenario, where no younger cohorts are smoking and smokers quit at an accelerated rate. The difference between the Smok and Trend scenarios shows that quitting among smokers is the most important cause of the increase in disability: smokers with disease try to stop. If they do not, their prognosis is poor and disability will be lowered by a very high mortality rate. But this is common to all curable diseases - quitting smoking is the single most important preventive and therapeutic action among smokers with disease. 
Figure 3. Change in ADLs among the disabled elderly in 2040 compared with 2008, smoking scenarios

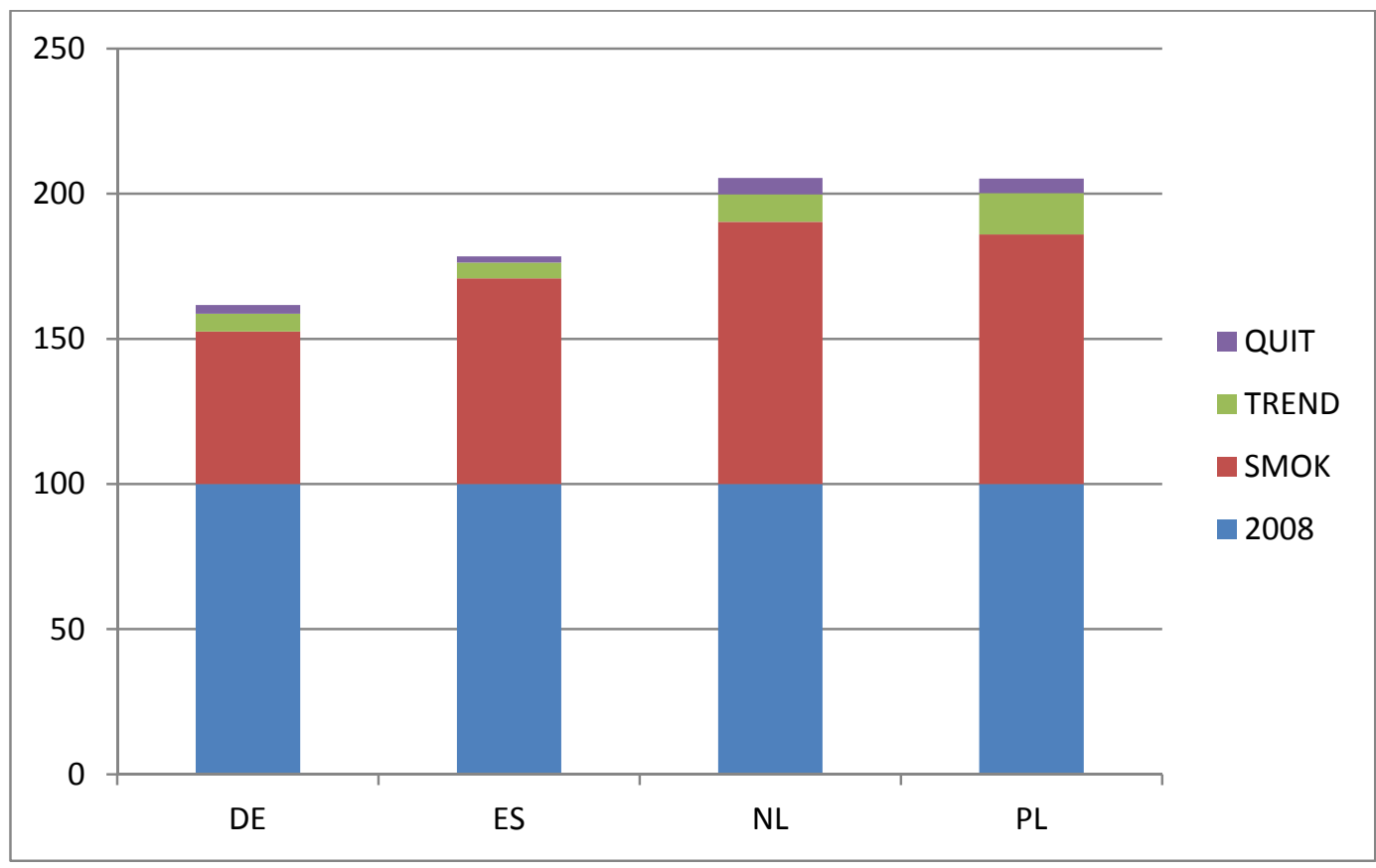

Notes: The smoking scenarios show the consequences of the Delay scenario adjusted for heterogeneity in smoking behaviour. In 'Smok', the prevalence of smoking remains constant at the values of the young cohorts in 2008. 'Trend' is a realistic scenario assuming a slowly declining prevalence ( $2 \%$ per year) and adding successful quitting at a rate of $2 \%$ per year. 'Quit' is an accelerated quitting scenario, where no new inflowing cohorts are smoking and smokers quit at accelerated rates.

\section{Policy implications and recommendations}

The scenarios show the overriding influence of demographic change on future disability. The demographic projections for 2040 are robust: in the life table, 95\% of babies will survive until age 55. Life extension is the second most important force driving the increase in disability. The simple linear forecasts of the EUROPOP scenarios project a period of unprecedented decline in mortality among those aged 55+ from the second half of the $20^{\text {th }}$ century to the future. Yet the predicted life expectancy among women aged 65 in 2040 is still lower in the EU than the actual female life expectancy in Japan at age 65 in 2009 (24.0 years); thus, this is not an unreasonable scenario.

Assuming a constant disability incidence with sharply decreasing mortality (the chronology scenario) would be pessimistic and not consistent with theories of ageing. For the time being, and for severe disability, there is strong support for more biological scenarios. ${ }^{3}$ At the same time, assuming sharply decreasing disability while little progress is observed in cognitive causes of disability may be too optimistic. Still, the numbers of life years lived with disability remained surprisingly constant in the Netherlands as in other countries (Maier, 2011). The intermediary Delay scenario is a somewhat more conservative estimate of the biological scenario, which is a safe basis for projections used in policy preparation.

The effects of changing risk factors on the prevalence of disability are surprisingly small. First, there is demographic inertia: it takes many years to replace populations. People start smoking as teenagers and they will die as smokers or quitters six decennia later. Second, every person born between 1943 and 1975 will add to the population of the elderly at risk of disability, but only a fraction of that population is at an increased risk by disabling lifestyles. If one-sixth is disabled when not obese but one-third is if

\footnotetext{
${ }^{3}$ See Cai and Lubitz (2007), Christensen et al. (2009), Freedman et al. (2004), Freedman, Martin and Schoeni (2002), Gill et al. (2010), Majer et al. (2011a), Manton, Gu and Ukraintseva (2005), Manton (2008), SagarduiVillamor et al. (2005).
} 
obese, and $20 \%$ are obese, the attributable risk is $3 \%$. If the prevalence of obesity doubles, from $20 \%$ to $40 \%$, the attributable risk doubles to $6 \%$ and the prevalence of disability increases from $20 \%$ to $23 \%$. If for instance in the Netherlands the population aged 65+ were to double from 100 to 200, there would be 47 disabled individuals among these 200 persons: 20 would be added because of the doubling of the population and 7 would be added because of doubled obesity. The numbers are relatively limited compared with the demographic increase. Note that the assumptions of both change (a doubling of the prevalence of obesity) and risk (a doubled risk) are extreme, and true increases in attributable risk would be smaller.

The effects of quitting smoking are associated with life extension. Smoking shortens life and shortens life with disability. Many smokers improve the prognosis of their disease considerably by quitting and extended survival by lifestyle modification can hardly be called a disadvantage. Yet even extreme scenarios would not add many disabled elderly persons.

A most important conclusion is that the future numbers of the disabled elderly can be forecasted robustly and will be determined for a large part by demographic change. Lowered mortality rates increase life expectancy, but being a result of progress, it is predominantly a life expectancy free of disability. Obesity increases disability, but only the added obese are at a higher risk. Successful antiobesity policies will lower the number of disabled elderly persons only modestly. Smokers suffer more from lethal diseases - but the population effects are small and mostly caused by smokers who do not quit. Successful policies that help smokers to quit will increase life expectancy, with the consequence of only a very moderate increase in the number of the disabled elderly.

Ageing will cause sharp increases in the numbers of the disabled elderly, but these increases are easily foreseeable over several decennia and planning for future resources can be initiated in a timely manner.

\section{Research parameters}

We assumed equal mortality trends for disabled and non-disabled persons, and for persons with or without different risk statuses. This might not be true. Indeed, for dementia (a most important cause of disability), we can observe lower mortality at early stages but increased mortality at later clinical stages among more highly educated people - a consequence of more successful adaptation to cognitive decline by highly educated persons (Reuser, Willekens and Bonneux, 2011). More highly educated people can stave off clinical dementia until they reach advanced stages of severe disease and poor prognosis. Future research should focus more on postponing disability by promoting adaptation to the unavoidable impairments of old age.

The data on the prevalence of disability are very weak. The prevalence of ADL disability is highest among the oldest old, but data on prevalence are scarce and trend data nearly absent. We have more confidence in the reliability of the modelled trends than in the national point estimates of ADL disability for 2008. With longer follow-up, SHARE can inform us about trends in prevalence, and maybe even incidence. Yet the quality of the follow-up will be of utmost importance. Disability and mortality are easily lost in follow-up, which will bias incidence, prevalence and the survival of disabled persons towards lower values. We strongly advise the investment of more resources in the SHARE project, and particularly in the follow-up of SHARE participants in order to collect reliable data. 


\section{References}

Al Mamun, A., A. Peeters, J. Barendregt, F. Willekens, W. Nusselder and L. Bonneux (2004), "Smoking decreases the duration of life lived with and without cardiovascular disease: A life course analysis of the Framingham Heart Study”, European Heart Journal, 25(5): 409-15.

Al Snih, S., K.J. Ottenbacher, K.S. Markides, Y. Kuo, K. Eschbach and J.S. Goodwin (2007), “The effect of obesity on disability vs mortality in older Americans", Archive of Internal Medicine, 167(8): 774-780.

Alley, D.E. and V.W. Chang (2007), "The changing relationship of obesity and disability, 19882004”, Journal of the American Medical Association, 298(17): 2066-2067.

Barendregt, J.J., L. Bonneux and P.J. Van der Maas (1994), "Health expectancy: An indicator for change? Technology Assessment Methods Project Team”, Journal of Epidemiology and Community Health, 48(5): 482-487.

Barendregt, J.J., L. Bonneux and P.J. Van der Maas (1997), “The health care costs of smoking”, New England Journal of Medicine, 337: 1052-1057.

Bobak, M., M. Kristenson, H. Pikhart and M. Marmot (2004), "Life span and disability: A cross sectional comparison of Russian and Swedish community based data”, Bmj, 329: 767.

Cai, L. and J. Lubitz (2007), "Was there compression of disability for older Americans from 1992 to 2003?”, Demography, 44(3): 479-495.

Christensen, K., G. Doblhammer, R. Rau and J.W. Vaupel (2009), “Ageing populations: The challenges ahead", Lancet, 374(9696): 1196-1208.

Freedman, V.A., E. Crimmins, R.F. Schoeni, B.C. Spillman, H. Aykan, E. Kramarow, K. Land, J. Lubitz, K. Manton, L.G. Martin, D. Shinberg and T. Waidmann (2004), "Resolving inconsistencies in trends in old-age disability: Report from a technical working group", Demography, 41(3): 417-441.

Freedman, V.A., L.G. Martin and R.F. Schoeni (2002), "Recent trends in disability and functioning among older adults in the United States: A systematic review", Journal of the American Medical Association, 288(24): 3137-3146.

Giannakouris, K. (2010), "Regional Population Projections EUROPOP2008: Most EU regions face older populations profile in 2030", Population and social conditions, Eurostat Statistics in Focus, 2010/1.

Gill, T.M., E.A. Gahbauer, L. Han and H.G. Allore (2010), “Trajectories of disability in the last year of life”, New England Journal of Medicine, 362: 1173-1180.

Hofman, A., M.M. Breteler, C.M. van Duijn, H.L. Janssen, G.P. Krestin, E.J. Kuipers, B.H. Stricker, H. Tiemeier, A.G. Uitterlinden, J.R. Vingerling and J.C. Witteman (2009), "The Rotterdam Study: 2010 objectives and design update”, European Journal of Epidemiology, 24(9): 553-72.

Katz, S., A.B. Ford, R.W. Moskowitz, B.A. Jackson and M.W. Jaffe (1963), "Studies of Illness in the Aged, The Index of ADL: A Standardized Measure of Biological and Psychosocial Function”, Journal of the American Medical Association, 185(12): 914-919.

Maier, I. (2011), Modeling and forecasting health expectancy: Theoretical framework and application, Netspar discussion 01/2011-009, Network for Studies on Pensions, Aging and Retirement (http://www.netspar.nl/publications_academic_papers.htm).

Majer, I.M., W.J. Nusselder, J.P. Mackenbach, B. Klijs and P.H. van Baal (2011a), "Mortality risk associated with disability: A population-based record linkage study", American Journal of Public Health, 101(12): e9-e15. 
Majer, I.M., W.J. Nusselder, J.P. Mackenbach and A.E. Kunst (2011b), "Life expectancy and life expectancy with disability of normal weight, overweight, and obese smokers and nonsmokers in Europe”, Obesity (Silver Spring), 19: 1451-1459.

Manton, K.C., X.L. Gu and S.V. Ukraintseva (2005), "Declining prevalence of dementia in the U.S. elderly population”, Advances in Gerontology, 16: 30-37.

Manton, K.G. (1982), “Changing concepts of morbidity and mortality in the elderly population”, Milbank Memorial Fund Quarterly, Health and Society, 60: 183-244.

Manton, K.G. (2008), "Recent Declines in Chronic Disability in the Elderly U.S. Population: Risk Factors and Future Dynamics”, Annual Review of Public Health, 29: 91-113.

Mitnitski, A.B., J.E. Graham, A.J. Mogilner and K. Rockwood (2002), "Frailty, fitness and late-life mortality in relation to chronological and biological age”, BMC Geriatrics, 2: 1.

Olshansky, S. J., M.A. Rudberg, B.A. Carnes, B.A. Cassel and J.A. Brady (1991), “Trading off longer life for worsening health: The expansion of morbidity hypothesis”, Journal of Ageing and Health, 3(2): 194-216.

Payne, G., A. Laporte, R. Deber and P.C. Coyte (2007), "Counting backward to health care's future: Using time-to-death modeling to identify changes in end-of-life morbidity and the impact of aging on health care expenditures”, Milbank Quarterly, 85(2): 213-57.

Peeters, A., L. Bonneux, W.J. Nusselder, C. De Laet and J.J. Barendregt (2004), “Adult obesity and the burden of disability throughout life", Obesity Research, 12: 1145-1151.

Reuser, M., L.G. Bonneux and F.J. Willekens (2009), "Smoking Kills, Obesity Disables: A Multistate Approach of the US Health and Retirement Survey”, Obesity (Silver Springs), 17(4): 783-789.

Reuser, M., F.J. Willekens and L. Bonneux (2011), "Higher education delays and shortens cognitive impairment: A multistate life table analysis of the US Health and Retirement Study", European Journal of Epidemiology, 26(5): 395-403.

Sagardui-Villamor, J., P. Guallar-Castillon, M. Garcia-Ferruelo, J.R. Banegas and F. RodriguezArtalejo (2005), “Trends in disability and disability-free life expectancy among elderly people in Spain: 1986-1999”, Journal of Gerontology, Series A, Biological Sciences and Medical Sciences, 60(8): 1028-34.

Sturm, R., J.S. Ringel and T. Andreyeva (2004), “Increasing obesity rates and disability trends”, Health Affairs, 23: 199-205.

Van der Gaag, N., G. Bijwaard, J. de Beer and L. Bonneux (2012), "Forecasting long-term care need of elderly using a multistate projection model", submitted.

Walter, S., A. Kunst, J. Mackenbach, A. Hofman and H. Tiemeier (2009), "Mortality and disability: The effect of overweight and obesity”, International Journal of Obesity, 33(12): 1410-1418. 


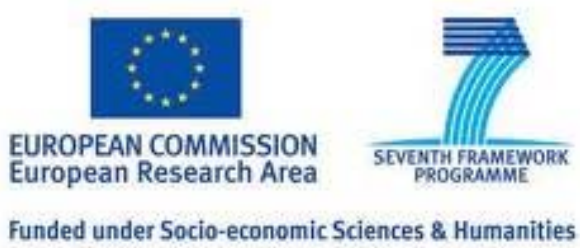

Funded under Socio-economic Sciences \& Humanities

\section{ANCIEN}

Assessing Needs of Care in European Nations

FP7 HEALTH-2007-3.2-2

L aunched in January 2009, ANCIEN is a research project financed under the 7th EU Research Framework Programme. It runs for a 44-month period and involves 20 partners from EU member states. The project principally concerns the future of long-term care (LTC) for the elderly in Europe and addresses two questions in particular:

1) How will need, demand, supply and use of LTC develop?

2) How do different systems of LTC perform?

The project proceeds in consecutive steps of collecting and analysing information and projecting future scenarios on long-term care needs, use, quality assurance and system performance. State-of-the-art demographic, epidemiological and econometric modelling is used to interpret and project needs, supply and use of long-term care over future time periods for different LTC systems.

Work Packages. The project started with collecting information and data to portray long-term care in Europe (WP 1). After establishing a framework for individual country reports, including data templates, information was collected and typologies of LTC systems were created. The collected data will form the basis of estimates of actual and future long term care needs in selected countries (WP 2). WP 3 builds on the estimates of needs to characterise the response: the provision and determinants of formal and informal care across European long-term care systems. Special emphasis is put on identifying the impact of regulation on the choice of care and the supply of caregivers. WP 6 integrates the results of WPs 1, 2 and 3 using econometric micro and macro-modelling, translating the projected needs derived from WP2 into projected use by using the behavioral models developed in WP3, taking into account the availability and regulation of formal and informal care and the potential use of technological developments.

On the back of projected needs, provisions and use in European LTC systems, WP 4 addresses developing technology as a factor in the process of change occurring in long-term care. This project will work out general principles for coping with the role of evolving technology, considering the cultural, economic, regulatory and organisational conditions. WP 5 addresses quality assurance. Together with WP 1, WP 5 reviews the policies on LTC quality assurance and the quality indicators in the EU member states, and assesses strengths, weaknesses, opportunities and threats of the various quality assurance policies. Finally WP 7 analyses systems performance, identifying best practices and studying trade-offs between quality, accessibility and affordability.

The final result of all work packages is a comprehensive overview of the long term care systems of EU nations, a description and projection of needs, provision and use for selected countries combined with a description of systems, and of quality assurance and an analysis of systems performance.

\section{Principal and Partner Institutes}

CEPS is responsible for administrative coordination and dissemination of the general results (WP 8 and 9). The Belgian Federal Planning Bureau (FPB) and the Netherlands Bureau for Economic Policy Analysis (CPB) are responsible for scientific coordination. Other partners include: German Institute for Economic Research (DIW); Netherlands Interdisciplinary Demographic Institute (NIDI); Fundación de Estudios de Economía Aplicada (FEDEA); Consiglio Nazionale delle Ricerche (CNR); Universitá Luiss Guido CarliLuiss Business School (LUISS-LBS); Institute for Advanced Studies (IHS); London School of Economics and Political Science- Personal Social Services Research Unit (PSSRU); Istituto di Studi e Analisi Economica (ISAE); Center for Social and Economic Research (CASE); Institute for Economic Research (IER); Social Research Institute (TARKI); The Research Institute of the Finnish Economy (ETLA); Université de Paris-Dauphine-Laboratoire d’Economie et de Gestion des organisations de Santé (DAUPHINE- LEGOS); University of Stockholm, Department of Economics; Karolinska InstituteDepartment of Medecine, Clinical Epidemiology Unit ; Institute of Economic Research, Slovak Academy of Sciences (SAS-BIER); Center for Policy studies (PRAXIS). Most of the ANCIEN partners are members of the European Network of Economic Policy Research Institutes (ENEPRI). 